\title{
Can Rheumatoid factor and Anti-cyclic citrullinated peptides predict true remission in rheumatoid arthritis patients? Study of relationship between autoantibodies levels and muskuloskelatal ultrasound findings in a sample cohort of Egyptian patients in clinical remission
}

Eman Hassan Al Sayed

University of Alexandria

Doaa Shaker Amin ( $\sim$ doaashaker74@gmail.com )

University of Alexandria

\section{Research Article}

Keywords: Rheumatoid arthritis, Rheumatoid factor, Anti-cyclic citrullinated peptides, muskuloskelatal ultrasound, remission.

Posted Date: March 15th, 2021

DOI: https://doi.org/10.21203/rs.3.rs-324261/v1

License: (c) (1) This work is licensed under a Creative Commons Attribution 4.0 International License. Read Full License 


\section{Abstract}

\section{Background}

True remission is the ultimate goal for rheumatoid arthritis (RA) therapy. Our aim was to investigate the relationship between serum levels of rheumatoid factor (RF) and anti-cyclic citrullinated peptides (AntiCCP) and ultrasonographic (US) findings in Egyptian RA patients in clinical remission.

\section{Methods}

Using data from a cross-sectional study on 50 RA patients in clinical remission or low disease activity (LDA) as defined by disease activity score (DAS28-ESR) cutoff points, performed in Alexandria University Hospital; we analyzed statistical relationships and correlations between RF, Anti-CCP) and Gray Scale (GS) and Power Doppler (PD) US using US7 score. US remission was defined as on a GS $\leq 1$ and PD $=0$.

\section{Results}

Among 34 patients in clinical remission, $61.8 \%$ (21) of patients in clinical remission were in ultrasonographic remission, and $38.2 \%$ (13) of patients in clinical remission had subclinical ultrasonographic activity. Patients in clinical remission with US remission had significantly higher Anti$\operatorname{CCP}(p=0.006)$ but not RF ( $p=0.086)$, than those in clinical remission with US subclinical activity. AntiCCP positively correlated with synovitis score by power Doppler US (PDUS) ( $r s=0.553, p=0.001$ ), and tenosynovitis/paratenonitis score by gray scale US(GSUS) ( $r s=0.389, p=0.023$ ).

\section{Conclusion}

We demonstrated that patients in clinical RA remission with subclinical US activity had higher serum levels of Anti-CCP, but not RF. Such an association should guide further treatment decisions for those patients.

\section{Background}

Achieving rheumatoid arthritis (RA) disease remission is becoming an imperative goal presently, thanks to the revolutionary treatment protocols that have been introduced to the disease management in the past twenty years ${ }^{(1,2)}$. Although reaching point remission is a pivotal step in judging treatment success, sustained disease remission will remain the ultimate outcome that both patients and clinicians long to achieve. ${ }^{(3)}$

Disease remission has been described in many aspects; including clinical, imaging and immunologic remission. Clinical remission depends on the use of composite indices that include joint counts, acute phase reactants and pain assessment measures. These indices can be stringent such as simplified disease activity index (SDAI), or less stringent in assessing disease remission as disease activity score (DAS28). ${ }^{(4,5)}$ However, they were proved to be lacking sensitivity to detect low levels of inflammation in 
many studies. ${ }^{(6)}$ Musculoskeletal ultrasonography (MSUS) has been demonstrated to detect subclinical synovitis not appreciated by routine clinical or laboratory assessments. ${ }^{(7)}$ Moreover, it was recently suggested that they have the ability to predict the duration of disease remission and the occurrence of flares. $(8,9)$

Beside the pathogenic and diagnostic functions of autoantibodies in RA patients, rheumatoid factor (RF) and anti-cyclic citrullinated peptides (Anti-CCP) have a clear association with the disease inflammatory process and the progression of structural damage, which emphasizes their role in the disease prognosis. $(10,11)$ Serum levels of RF and Anti-CCP may even change during treatment in some patients who have good clinical response. ${ }^{(12)}$ Although patients may continue having high concentrations of auto antibodies, studies proved that this does not prevent the occurrence of clinical remission. Yet, Anti-CCP positive patients seemed to face more flares. ${ }^{(10,13)}$

Recently, many studies proved the presence of subclinical synovitis- as detected by MSUS- in the joints of RA patients in clinical remission regardless the tightness of the used indices. Little evidence is present to analyze the association between autoantibodies and MSUS patterns in joints of RA patients who achieved clinical remission.

\section{Methods}

We performed secondary analysis from a cross-sectional study ${ }^{(14)}$ that included 50 Egyptian patients; 37 (74\%) females and 13 (26\%) males) with RA, diagnosed according the ACR/EULAR 2010 criteria for diagnosis of RA ${ }^{(15)}$, and fulfilled the cut-off values of clinical remission or low disease activity (LDA) according to DAS28-ESR score. ${ }^{(16,17)}$ The patients were recruited from those attending the Outpatient Clinic of Physical Medicine, Rheumatology and Rehabilitation Department and the Rheumatology and Immunology unit, Internal Medicine department, Faculty of Medicine, Alexandria University, Patients with osteoarthritis, any systemic disease with inflammatory arthropathies and hepatitis C virus (HCV) arthritis were excluded. An informed consent was given by each patient and the source study was approved by the ethics committee of the Faculty of Medicine. ${ }^{(14)}$

\section{Clinical assessment}

All patients were subjected to full history taking, including: disease duration, duration of clinical remission or low disease activity and full drug history. The patient's general health was evaluated using a Visual Analog Scale (VAS) of $100 \mathrm{~mm}$, in addition to complete physical examination including 28- tender joint count (28-TJC) and 28 swollen joint count (28-SJC). Disease activity was then assessed using DAS28ESR score. $(16,17)$

Clinical remission was defined as a DAS28-ESR score of $<2.6$, while LDA as a DAS28-ESR score of $\geq 2.6$ and $\leq 3$. . $^{(17)}$ 
Drug history was collected from patients, including heir intaker of conventional disease modifying antirheumatic drugs (cDMARDs), biologic disease modifying anti-rheumatic drugs (bDMARDs) and glucocorticoids.

\section{Laboratory investigations}

All patients underwent routine laboratory workup; erythrocyte sedimentation rate (ESR), C-reactive protein (CRP) measurement, Rheumatoid Factor (RF) titre in IU/ml by nephelometry ${ }^{(18)}$, Anti-cyclic citrullinated peptide (Anti-CCP) titre in U/ml measured by automated ELISA technique ${ }^{(19)}$.

\section{Musculoskeletal ultrasonographic examination}

The Gray Scale (GS) and Power Doppler (PD) ultrasonography (US) examination was performed using high frequency broadband linear array transducer at 10-18 MHz. PD settings were optimized to enhance the sensitivity for detecting synovial vessels without or with minimal artifact ${ }^{(20)}$.

The US examination was performed in two perpendicular planes, according to EULAR guidelines ${ }^{(21)}$. We followed the OMERACT standardized definitions of US pathological findings ${ }^{(22)}$, and scored according to US7 score ${ }^{(23)}$

The US remission was defined as on a GS $\leq 1$ and $P D=0(24,25)$. While those patients with GSUS $>1$ and/or PDUS $\geq 1$ were considered to have ultrasonography activity.

\section{Statistical analysis}

Data were analyzed using IBM SPSS software package version 20.0. ${ }^{(26)}$ (Armonk, NY: IBM Corp). Qualitative data were described using number and percent. Quantitative data were described using range (minimum and maximum), mean, standard deviation and median. Mann Whitney (U) test for abnormally distributed quantitative variables, to compare between two studied groups. Spearman coefficient (rs) to correlate between two distributed abnormally quantitative variables. The significance of the obtained results was judged at the $5 \%$ level.

\section{Results}

\section{Patients characteristics}

We analysed the data of 50 RA patients, 37 (74\%) of whom were females and $13(26 \%)$ were males. Their mean age was $49.58 \pm 9.14$ years, disease duration mean was $6.75 \pm 3.82$ years.

There were 33(66\%) patients on conventional synthetic disease modifying drugs (cDMARDs) and 17 (34\%) were on biological disease modifying drugs (bDMARDs). Twenty-three patients (46\%) used glucocorticoids with a low dose ( $\leq 5 \mathrm{mg} /$ day) as a part of tapering regimen or during bridging to bDMARDS. Twenty-seven patients (54\%) did not use any glucocorticoids (table 1$)$. ${ }^{(14)}$ 
Patients had a mean ESR of $12.48 \pm 4.15$ and mean CRP of $2.65 \pm 1.46 .7(14 \%)$ of the patients were RF negative patients and 43(86\%) RF positive patients. RF value ranged from $10.6-678 \mathrm{IJ} / \mathrm{ml}$, with a median of $45.95 \mathrm{IU} / \mathrm{ml}$. The Anti-CCP of the studied patients ranged from 2.8-2940 U/ml, with a median of 36.5 $\mathrm{U} / \mathrm{ml}$. There were 21 (42\%) Anti-CCP negative patients, and 29 (58\%) Anti-CCP positive patients.

Thirty-four (68\%) patients were in clinical remission and 16 (32\%) were in low disease activity according to cutoff values of DAS28-ESR score, which had a mean of $2.52 \pm 0.39$ (table 1).

\section{MSUS characteristics}

As examined by the US7 score, 21 (42\%) patients were found to be in ultrasonographic (US) remission, while 29 patients (58\%) were found to have subclinical ultrasonographic activity. All patients in LDA showed subclinical US activity, while $61.8 \%$ (21) of patients in clinical remission were in ultrasonographic remission, and $38.2 \%$ (13) of patients in clinical remission had a degree of subclinical ultrasonographic activity (table 2).

To test the relationship between the ultrasonographic findings and the autoantibodies levels, the comparison between patients in US remission and those with activity yielded a statistically significant difference for both RF $(p=0.03)$ and Anti-CCP $(p=0.021)$; where patients with US activity had higher autoantibodies levels (table 3 ). Further comparison revealed a statistically significant difference between patients in clinical remission with US remission and those in clinical remission with US subclinical activity; regarding Anti-CCP only ( $p=0.006)$, but not RF ( $p=0.086)$ (table 4). Patients in clinical remission with subclinical US activity had higher Anti-CCP. This latter group of patients included $7(53.8 \%)$ males and $6(46.2 \%)$ females, only $3(23.1 \%)$ of the patients had RF negative and $10(76.9 \%)$ were RF positive, 8 $(61.5 \%)$ of which had highly positive RF (>3 times upper limit normal-ULN). The Anti-CCP in this group was positive in 11 (84.6\%) and negative in $2(15.4 \%), 9(69.2 \%)$ patients had highly positive Anti-CCP (>3 times ULN). In addition, in the same group 7 (53.8\%) were treated with cDMARDS and 6 (46.2\%) with bDMARDS (table 5).

Based on the previous results, we examined the correlation between Anti-CCP and US7 score results in the aforementioned group, this proved a strong positive correlation between Anti-CCP and synovitis score by power Doppler US (PDUS) ( $r s=0.553, p=0.001$ ), and a similar positive correlation between Anti-CCP and tenosynovitis/paratenonitis score by gray scale US(GSUS) ( $r=0.389, p=0.023$ ); while none of the US7 score components correlated with Anti-CCP in patients in true remission (table 6).

\section{Conclusion}

Our study demonstrated that patients in clinical RA remission with subclinical US activity had higher serum levels of Anti-CCP. Since both have been proved to be related to joint damage progression; Such an association should guide the change treatment options while managing those patients, in order to decrease the incidence of relapse and offer an optimum disease outcome. 


\section{Discussion}

The occurrence of disease relapse is not an infrequent event in RA patients, even in those with sustained or prolonged periods of remission. Our cross-sectional study demonstrated the association between serum levels of auto antibodies, RF and Anti-CCP, and the presence of subclinical US signals in the joints of RA patients classified as being in clinical remission or LDA. Previous studies proved Anti-CCP to be a strong predictor of radiographic progression in RA patients in remission ${ }^{(27)}$. Similarly, residual PDUS activity in the clinically inactive joints can predict joint damage and the occurrence of erosions. $(28,29)$ Ramirez et al found that US-defined synovitis in RA patients in clinical remission was immunopathologically characterized by persistent macrophage infiltration and increased vascularity reflected by the appearance of PD signals upon US examination. ${ }^{(30)}$ This association we proved would make the probability of relapse very high, at any point of time during remission.

Furthermore, we demonstrated that patients in clinical remission with high PDUS synovitis score had elevated Anti-CCP through a strong positive correlation, such a correlation was absent in patients in patients with combined clinical and US remission. The former group of patients mostly had a very high titer of Anti-CCP ( $>3$ times ULN). This finding was in concordance Lukas et al. who concluded that RA patients in clinical remission are more likely to have persistence of PDUS synovitis if they have anti-CCP.

(31) Such a correlation may have an important role in predicting further disease outcome, and a crucial impact on treatment strategies for patients in remission.

On the other hand, Boetres at al. who investigated the seroreversion rates in patients with long-standing DMARD-free status, found that antibodies disappearance is not a frequent occurrence in such patients and stated that "this form of immunological remission should therefore not be a treatment target". (32) However, they depended only on the clinical disappearance of signs and symptoms of synovitis, which is well known to be lacking in describing true remission and missing the advantage of US of detecting the subclinical synovitis that may be a clue to disease relapse that happened to a number of their patients.

We believe that if the ultimate goal of treat to target therapy is actually a longstanding drug-free "true" remission, then the association between high levels of serum antibodies and US detected subclinical synovitis should be put in consideration while designing treatment plans for RA patients even during remission.

A limiting point in our study was its cross-sectional nature, that prevented us from studying the association of serum antibodies and US detected subclinical synovitis on a longterm during remission, therefor longitudinal studies are mandatory in this respect. Another caveat is the small number of participants that constituted a statistical challenge, this is attributed to the fact that this was a singlecenter study.

\section{Abbreviations}


28-SJC: 28 swollen joint count

28-TJC: 28- tender joint count

Anti-CCP: anti-cyclic citrullinated peptides

bDMARDs: biologic disease modifying anti-rheumatic drugs

CDMARDs: conventional disease modifying anti-rheumatic drugs

CRP: C-reactive protein

DAS28-ESR: disease activity score

ESR: erythrocyte sedimentation rate

GS: Gray Scale

HCV: hepatitis C virus

LDA: low disease activity

MSUS: Musculoskeletal ultrasonography

PD: Power Doppler

$\mathrm{RA}$ : rheumatoid arthritis

RF: rheumatoid factor

SDAl: simplified disease activity index

US: ultrasonographic

VAS: Visual Analog Scale

\section{Declarations}

\section{Availability of data and materials}

The data utilized are accessible from the corresponding author upon reasonable request.

\section{Ethics declarations}

The source study was approved by the ethics committee of the Faculty of Medicine, University of Alexandria. 


\section{Competing interests}

The authors declare that they have no competing interests.

\section{Funding}

No funding was received for this study.

\section{Authors' contribution}

Both authors contributed to the data analysis, interpretation and drafting this manuscript.

\section{Acknowledgement}

Not applicable

\section{References}

1. Shammas RM, Ranganath VK, Paulus HE. Remission in rheumatoid arthritis. Curr Rheumatol Rep. 2010;12(5):355-62.

2. Smolen JS, Aletaha D, Bijlsma JW, Breedveld FC, Boumpas D, Burmester G, Combe B, Cutolo M, De Wit M, Dougados M, Emery P. Treating rheumatoid arthritis to target: recommendations of an international task force. Ann Rheum Dis. 2010;69(4):631-37.

3. Ajeganova S, Huizinga T. Sustained remission in rheumatoid arthritis: latest evidence and clinical considerations. Ther Adv Musculoskelet Dis. $2017 ; 9(10): 249-62$.

4. Salaffi F, Ciapet A. Clinical disease activity assessments in rheumatoid arthritis. Int. J Clin Rheumatol. 2013; 8(3):347-60.

5. Yazici Y, Simsek Tools for monitoring remission in rheumatoid arthritis: any will do, let's just pick one and start measuring. Arthritis Res Ther. 2013;15(1):104.

6. Brown AK, Quinn MA, Karim Z, Conaghan PG, Peterfy CG, Hensor E et al. Presence of significant synovitis in rheumatoid arthritis patients with disease-modifying antirheumatic drug-induced clinical remission: evidence from an imaging study may explain structural progression. Arthritis Rheum. 2006;54(12):3761-73.

7. Abdelghani KB, Miladi S, Souabni L, Kassab S, Chekili S, Laatar A, Zakraoui L. Role of ultrasound in assessing remission in rheumatoid arthritis. Diagnostic and interventional imaging. $J$ Ultrason. 2015;96(1):3-10.

8. Yoshimi R, Hama M, Takase K, Ihata A, Kishimoto D, Terauchi K, et al. Ultrasonography is a potent tool for the prediction of progressive joint destruction during clinical remission of rheumatoid arthritis. Mod Rheumatol 2013;23:456-65.

9. Zufferey P, Scherer A, Nissen MJ, Ciurea A, Tamborrini G, Brulhart L, Blumhardt S, Toniolo M, Möller B, Ziswiler HR. Can ultrasound be used to predict loss of remission in patients with RA in a real-life 
setting? A multicenter cohort study. J Rheumatol. 2018 Jul 1;45(7):887-94.

10. Bugatti S, Manzo A, Montecucco C, Caporali R. The clinical value of autoantibodies in rheumatoid arthritis. Front Med. 2018; 3;5:339.

11. Reed E, Hedström AK, Hansson M, Mathsson-Alm L, Brynedal B, Saevarsdottir S, Cornillet M, Jakobsson PJ, Holmdahl R, Skriner K, Serre G. Presence of autoantibodies in "seronegative" rheumatoid arthritis associates with classical risk factors and high disease activity. Arthritis Res Ther. 2020;22(1):1-1.

12. Aletaha D, Blüml S. Therapeutic implications of autoantibodies in rheumatoid arthritis. RMD open. 2016 May 1;2(1):e000009.

13. da Mota LM, dos Santos Neto LL, de Carvalho JF, Pereira IA, Burlingame R, Ménard HA, Laurindo IM. The presence of anti-citrullinated protein antibodies (ACPA) and rheumatoid factor on patients with rheumatoid arthritis (RA) does not interfere with the chance of clinical remission in a follow-up of 3 years. Rheumatol Int. 2012;32(12):3807-12.

14. Amin DS, Ibrahim IK, Afifi AH, El-Hadidi AS, Al Sayed EH. High resolution ultrasonography and power doppler in evaluation of disease activity of rheumatoid arthritis patients in clinical remission or low disease activity. studies. JMRI. 2020; 41(1):6-15.

15. Aletaha D, Neogi T, Silman AJ, Funovits J, Felson DT, Bingham CO. 2010 Rheumatoid Arthritis Classification Criteria. An American College of Rheumatology/European League Against Rheumatism. Collaborative Initiative. Arthritis Rheum. 2010; 62(9):2569-2581.

16. Fleischmann R, van der Heijde D, Koenig AS, Pedersen R, Szumski A, et al. How much does Disease Activity Score in 28 joints ESR and CRP calculations underestimate disease activity compared with the Simplified Disease Activity Index? Ann Rheum Dis. 2015 ;74(6):1132-39.

17. DAS-Score.nl [internet]. DAS28: Layout 1 [pdf]; 2009 February 5. Available from: http://www.iche.edu/newsletter/DAS28.pdf.

18. Saraux A, Berthelot JM, Chalès G, Le Henaff C, Mary JY, Thorel JB, et al. Value of laboratory tests in early prediction of rheumatoid arthritis. Arthritis Rheum. 2002;47(2):155-165.

19. Kim S, Kim JH, Lee JH, Kim HS. Evaluation of three automated enzyme immunoassays for detection of anti-cyclic citrullinated peptide antibodies in qualitative and quantitative aspects. Rheumatol. 2010; 49(3):450-7.

20. Dale J, Purves D, Mcconnachie A,Mcinnes I, and Porter D. Tightening Up? Impact of musculoskeletal ultrasound disease activity assessment on early rheumatoid arthritis patients treated using a treat to target strategy. Arthritis Care \& Res. 2014; 66(1):19-26.

21. Backhaus M, Burmester GR, Gerber T, Grassi W, Machold KP, Swen WA, et al. Guidelines for musculoskeletal ultrasound in rheumatology. Ann Rheum Dis. 2001; 60(7):641-9.

22. Wakefield RJ, Balint PV, Szkudlarek M, Filippucci E, Backhaus M, et al. OMERACT 7 special interest group; musculoskeletal ultrasound including definitions for ultrasonographic pathology. J Rheumatol. 2005; 32(12): 2485-92. 
23. Backhaus M, Ohrndorf S, Kellner H, Strunk J, Backhaus TM, Hartung W. Evaluation of a Novel 7-Joint Ultrasound Score in Daily Rheumatologic Practice: A Pilot Project. Arthritis Rheum. 2009 ;61(9):11941201.

24. Lene Terslev, Esperanza Naredo, Philippe Aegerter, Richard J Wakefield, Marina Backhaus, Peter Balint. Scoring ultrasound synovitis in rheumatoid arthritis: a EULAROMERACT ultrasound taskforcePart 2: reliability and application to multiple joints of a standardized consensus-based scoring system RMD Open. 2017; 3:e000427.

25. van der Ven M, Kuijper TM, Gerards AH, Tchetverikov I, Weel AE, et al. No clear association between ultrasound remission and health status in rheumatoid arthritis patients in clinical remission. van Zeben J. Rheumatol. $2017 ; 56(8): 1276-81$.

26. Kirkpatrick LA, Feeney BC. A simple guide to IBM SPSS statistics for version 20.0. Student ed. Belmont, Calif.: Wadsworth, Cengage Learning; 2013.

27. Koga T, Okada A, Fukuda T, Hidaka T, Ishii T, Ueki Y, et al. Anti-citrullinated peptide antibodies are the strongest predictor of clinically relevant radiographic progression in rheumatoid arthritis patients achieving remission or low disease activity: A post hoc analysis of a nationwide cohort in Japan. PLoS One.2017; 12(5): e0175281.

28. Raffeiner B, Grisan E, Botsios C, Stramare R, Rizzo G, Bernardi L, et al. Grade and location of power Doppler are predictive of damage progression in rheumatoid arthritis patients in clinical remission by anti-tumour necrosis factor a Rheumatol.2017; 56(8):1320-25.

29. Anari H, Enteshari-Moghaddam A, Pourfarzi F, Ramazani N. Diagnostic value of ultrasonography in the detection of bone brosions in patients with rheumatoid arthritis: a comparison with conventional radiography. Mediterr J Rheumatol. 2019;30(2):110-3.

30. Ramírez J, Celis R, Usategui A, Ruiz-Esquide V, Faré R, Cuervo A, et al. Immunopathologic characterization of ultrasound-defined synovitis in rheumatoid arthritis patients in clinical remission. Arthritis Res Ther. 2016; 18:74.

31. Filippi N, Lukas C, Morel J, Combe B, Mouterde G, Lapeyronie CH. Predictors of persistence of power doppler ultrasound synovitis in rheumatoid arthritis patients in clinical remission. Ann Rheum Dis 2015; 74(2):887.

32. Boeters D M, Burgers L E, Toes R E M, van der Helm-van Mil A H M. Does immunological remission, defined as disappearance of autoantibodies, occur with current treatment strategies? A long-term follow-up study in rheumatoid arthritis patients who achieved sustained DMARD-free status. Ann Rheum Dis. 2019; 78(11): 1497-1504

\section{Tables}

Table (1): Demographic, clinical and laboratory characteristics of Egyptian patients with rheumatoid arthritis in clinical remission or LDA: 


\begin{tabular}{|c|c|}
\hline & Patients $(n=50)$ \\
\hline Age(years) & \\
\hline Range & $27-65$ \\
\hline Mean \pm SD & $49.58 \pm 9.14$ \\
\hline Gender & \\
\hline Male [n (\%)] & $13(26)$ \\
\hline Female $[\mathrm{n}(\%)]$ & $37(74)$ \\
\hline Disease duration (years) & \\
\hline Range & $1.5-17$ \\
\hline Mean \pm SD & $6.75 \pm 3.82$ \\
\hline TJC & \\
\hline Range & $0-3$ \\
\hline Mean \pm SD & $1.26 \pm 0.83$ \\
\hline SJC & \\
\hline Range & $0-2$ \\
\hline Mean \pm SD & $0.14 \pm 0.4$ \\
\hline DAS28-ESR & \\
\hline Range & $1.7-3.17$ \\
\hline Mean \pm SD & $2.52 \pm 0.39$ \\
\hline Patients in clinical remission $[\mathrm{n}(\%)]$ & $34(68)$ \\
\hline Patients in LDA [n (\%)] & $16(32)$ \\
\hline ESR (mm/hour) & \\
\hline Range & $5-26$ \\
\hline Mean \pm SD & $12.48 \pm 4.15$ \\
\hline CRP (mg/dl) & \\
\hline Range & $0.7-7.3$ \\
\hline Mean \pm SD & $2.65 \pm 1.46$ \\
\hline $\mathrm{RF}(\mathrm{IU} / \mathrm{ml})$ & \\
\hline Range & $10.6-678$ \\
\hline Median & 45.95 \\
\hline Negative $(\leq 15.9)[\mathrm{n}(\%)]$ & $7(14)$ \\
\hline Positive (>15.9) [n (\%)] & $43(86)$ \\
\hline Anti-CCP (U/ml) & \\
\hline Range & $2.8-2940$ \\
\hline Median & 36.5 \\
\hline Negative $(<20)[\mathrm{n}(\%)]$ & $21(42)$ \\
\hline Positive $(\geq 20)[\mathrm{n}(\%)]$ & $29(58)$ \\
\hline bDMARDs [n (\%)] & $17(34)$ \\
\hline cDMARDs [n (\%)] & $33(66)$ \\
\hline Glucocorticoids [n (\%)] & $23(46)$ \\
\hline
\end{tabular}

TJC; tender joint count, SJC; swollen joint count, DAS; disease activity score, LDA; low disease activity, ESR; erythrocyte sedimentation rate, CRP; C reactive protein, RF; rheumatoid factor, Anti-CCP; anti-cyclic citrullinated peptide, bDMARD; biologic disease-modifying antirheumatic drugs, cDMARDS; conventional disease-modifying antirheumatic drugs.

Table (2): US7 results in patients in clinical remission with subclinical US $(n=13)$ 


\begin{tabular}{||l|c|c||}
\hline \hline \multicolumn{1}{||c|}{ US7 score } & Min. - Max. & Mean \pm SD. \\
\hline Synovitis score by GSUS $(\max 27)$ & $0.0-5.0$ & $1.98 \pm 1.29$ \\
\hline Synovitis score by PDUS (max 39$)$ & $0.0-3.0$ & $0.66 \pm 0.82$ \\
\hline Tenosynovitis/paratenonitis score by GSUS $(\max 7)$ & $0.0-3.0$ & $0.9 \pm 0.84$ \\
\hline Tenosynovitis/paratenonitis score by PDUS $(\max 21)$ & $0.0-2.0$ & $0.3 \pm 0.65$ \\
\hline Erosions score $(\max 14)$ & $0.0-3.0$ & $0.42 \pm 0.73$ \\
\hline \hline
\end{tabular}

Quantitative data was expressed using Min. - Max. , Mean \pm Sd.

Table (3): Comparison between patients in ultrasound remission and those with activity as measured by US7 score according to autoantibodies [AntiCCP \& RF] $(\mathrm{n}=50)$

\begin{tabular}{||c|c|c|c|c||}
\hline \hline & \multicolumn{2}{|c|}{ US7 score } & Test of Sig. & p \\
\cline { 2 - 3 } & $\begin{array}{c}\text { Remission } \\
(\mathbf{n}=\mathbf{2 1})\end{array}$ & $\begin{array}{c}\text { Activity } \\
(\mathbf{n}=\mathbf{2 9})\end{array}$ & \\
\hline $\begin{array}{c}\text { Anti-CCP } \\
\text { Min. - Max. }\end{array}$ & $2.8-278$ & $4.30-2940$ & $\mathrm{U}=$ & $0.021^{*}$ \\
Mean \pm SD. & $65.57 \pm 92.81$ & $633.3 \pm 993.4$ & $187.5^{*}$ & \\
Median & 17.5 & 80 & & \\
\hline RF & & $10.6-678$ & $\mathrm{U}=$ & $0.03^{*}$ \\
Min. - Max. & $11.5-112$ & $\begin{array}{c}10.5 \pm 163.9 \\
\text { Mean } \pm \text { SD. }\end{array} 36.88 \pm 25.63$ & $100.5 \pm 194^{*}$ & \\
Median & 23.4 & 54.3 & & \\
\hline \hline
\end{tabular}

U: Mann Whitney test

$\mathrm{p}$ : $\mathrm{p}$ value for comparing between the two categories

*: Statistically significant at $\mathrm{p} \leq 0.05$

Table (4): Comparison between patients in true remission and those with subclinical US activity according to Anti-CCP \& RF ( $\mathrm{n}=34$ cases) 


\begin{tabular}{|c|c|c|c|c|}
\hline & \multicolumn{2}{|c|}{ DAS28 \&US7 scores } & \multirow[t]{2}{*}{ Test of Sig. } & \multirow{2}{*}{$p$} \\
\hline & $\begin{array}{c}\text { True Remission } \\
(\mathrm{n}=21)\end{array}$ & $\begin{array}{c}\text { Subclinical Activity } \\
(\mathrm{n}=13)\end{array}$ & & \\
\hline \multicolumn{5}{|l|}{ Anti-CCP } \\
\hline Min. - Max. & $2.8-278$ & $6.50-2940$ & $\mathrm{U}=$ & $0.006^{*}$ \\
\hline $\begin{array}{l}\text { Mean } \pm \text { SD } \\
\text { Median }\end{array}$ & $\begin{array}{c}65.57 \pm 92.81 \\
17.5\end{array}$ & $\begin{array}{c}1151.48 \pm 1288.9 \\
89.2\end{array}$ & $59^{*}$ & \\
\hline \multicolumn{5}{|l|}{$\mathrm{RF}$} \\
\hline Min. - Max. & $11.5-112$ & $10.6-678$ & $\mathrm{U}=$ & 0.086 \\
\hline $\begin{array}{l}\text { Mean } \pm \text { SD } \\
\text { Median }\end{array}$ & $\begin{array}{c}36.88 \pm 25.63 \\
23.4\end{array}$ & $\begin{array}{c}150.82 \pm 233.87 \\
59.3\end{array}$ & 88 & \\
\hline
\end{tabular}

$\mathrm{U}$ : Mann Whitney test

$\mathrm{p}$ : $\mathrm{p}$ value for comparing between the two categories

*: Statistically significant at $\mathrm{p} \leq 0.05$

Table (5): Characteristics of patients in clinical remission with subclinical US $(n=13$ cases) 


\begin{tabular}{||l|c||}
\hline \hline & No. (\%) \\
\hline Gender & $7(53.8 \%)$ \\
\hline Male & $6(46.2 \%)$ \\
\hline Female & \\
\hline RF (IU/ml) & $3(23.1 \%)$ \\
\hline Negative $(\leq 15.9)$ & $10(76.9 \%)$ \\
\hline Positive (>15.9) & $5(38.5 \%)$ \\
\hline$\downarrow 3$ times ULN $(\leq 47.7)$ & $8(61.5 \%)$ \\
\hline$\uparrow 3$ times ULN $(>47.7)$ & $10.6-678.0$ \\
\hline Min. - Max. & $150.82 \pm 233.87$ \\
\hline Mean \pm SD. & 59.30 \\
\hline Median & \\
\hline Anti-CCP $(U / m l)$ & $2(15.4 \%)$ \\
\hline Negative $(<20)$ & $11(84.6 \%)$ \\
\hline Positive $(\geq 20)$ & $4(30.8 \%)$ \\
\hline$\downarrow 3$ times ULN $(<60)$ & $9(69.2 \%)$ \\
\hline$\uparrow 3$ times ULN $(\geq 60)$ & $6.50-2940.0$ \\
\hline Min. - Max. & $1151.48 \pm 1288.96$ \\
\hline Mean \pm SD. & 89.20 \\
\hline Median & $7(53.8 \%)$ \\
\hline Type of DMARD & \\
\hline bDMARDS & \\
\hline CDMARDS & \\
\hline \hline
\end{tabular}

Qualitative data were described using number and percentage.

Quantitative data was expressed using Min. - Max. , Mean \pm Sd. and median.

Table (6): Correlation between US7 score and Anti-CCP in patients in true remission and patients with subclinical US activity $(\mathrm{n}=34)$ 


\begin{tabular}{||l|c|c|c|c||}
\hline \hline \multicolumn{1}{|c|}{ US7 score } & \multicolumn{4}{c||}{ Anti-CCP } \\
\cline { 2 - 5 } & $\begin{array}{l}\text { True remission } \\
(\mathbf{n}=\mathbf{2 1})\end{array}$ & $\begin{array}{c}\text { Subclinical Activity } \\
(\mathbf{n}=13)\end{array}$ \\
\cline { 2 - 5 } & $\mathrm{r}_{\mathrm{s}}$ & $\mathbf{P}$ & $\mathrm{r}_{\mathrm{s}}$ & $\mathrm{P}$ \\
\hline Synovitis score by GSUS (max 27) & -0.225 & 0.461 & 0.330 & 0.057 \\
\hline Synovitis score by PDUS (max 39) & 0.550 & 0.051 & $0.553^{*}$ & $0.001^{*}$ \\
\hline Tenosynovitis/paratenonitis score by GSUS (max 7) & -0.200 & 0.513 & $0.389^{*}$ & $0.023^{*}$ \\
\hline Tenosynovitis/paratenonitis score by PDUS (max 21) & -0.345 & 0.236 & -0.043 & 0.808 \\
\hline Erosions score (max 14) & -0.153 & 0.618 & 0.176 & 0.319 \\
\hline \hline
\end{tabular}

$r_{\mathrm{s}}$ : Spearman coefficient

*: Statistically significant at $\mathrm{p} \leq 0.05$ 